\title{
Use of video-assisted thoracoscopic surgery in penetrating chest trauma
}

\author{
Laura L. Stafman, BA, ${ }^{\mathrm{a}}$ Luke G. Gutwein, MD, ${ }^{\mathrm{a}}$ and Darwin N. Ang, MD, PhD, MPH ${ }^{\mathrm{b}}$
}

A 27-year-old man, alert and previously healthy, was evaluated at the emergency department immediately after a laboratory explosion. Physical examination revealed normal hemodynamics, a burn injury to his face, and small lacerations across the patient's chest and abdomen. Visible glass was removed, and the lacerations were irrigated. Computed tomographic images of the chest, abdomen, and pelvis indicated the presence of a large foreign body in the musculature of the right side of the chest, extending into the upper lobe of the right lung (Figure 1). The patient underwent video-assisted thoracoscopic surgery on the right side of the chest and thoracostomy tube placement. He was found to have a foreign body penetrating the chest wall and right lung (Figure 2). Gross examination revealed glass, consistent with a beaker fragment. The patient was discharged home on postoperative day 4 with no complications.

As compared with thoracotomy, video-assisted thoracoscopic surgery has many advantages: lower incidence of wound and pulmonary complications, less analgesia required, a shorter time to resumption of normal activity, and higher patient satisfaction. ${ }^{1}$ Video-assisted thoracoscopic surgery has proved to be an alternative approach to treating patients in hemodynamically stable condition with blunt and penetrating thoracic injuries. In a metaanalysis, thoracoscopy was shown to prevent $62 \%$ of trauma patients from undergoing a thoracotomy or laparotomy, with a $2 \%$ complication rate and a $0.8 \%$ missed injury rate. $^{2}$

\section{References}

1. Ben-Nun A, Orlovsky MO, Best LA. Video-assisted thoracoscopic surgery in the treatment of chest trauma: long-term benefit. Ann Thorac Surg. 2007;83:383-7.

\footnotetext{
From the Department of Surgery, ${ }^{\text {a }}$ University of Florida, Gainesville, Fla; and the Department of Surgery, ${ }^{\mathrm{b}}$ University of South Florida, Tampa, Fla.

Disclosures: Authors have nothing to disclose with regard to commercial support.

Received for publication Jan 23, 2013; accepted for publication Feb 11, 2013; available ahead of print March 8, 2013.

Address for reprints: Luke G. Gutwein, MD, Department of Surgery, University of Florida, PO Box 100286, 1600 SW Archer Rd, Gainesville, FL 32610 (E-mail:

Gutwein@surgery.ufl.edu).

J Thorac Cardiovasc Surg 2013;146:979

$0022-5223 / \$ 36.00$

Copyright (c) 2013 by The American Association for Thoracic Surgery

http://dx.doi.org/10.1016/j.jtcvs.2013.02.009
}

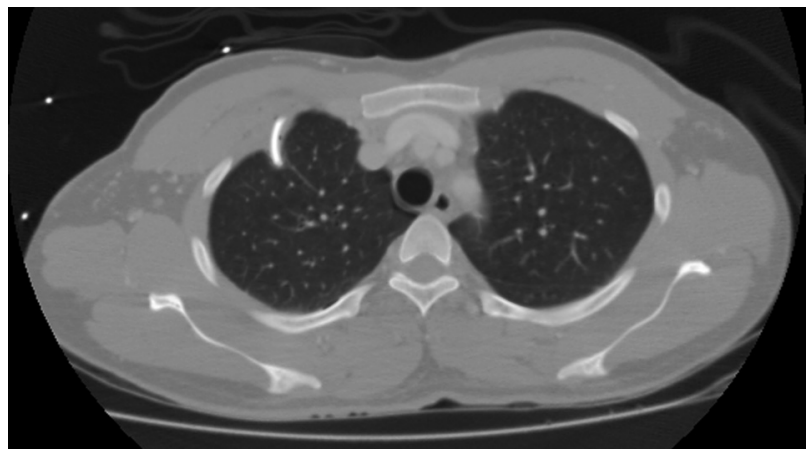

FIGURE 1. Computed tomographic scan of the chest showing foreign body.

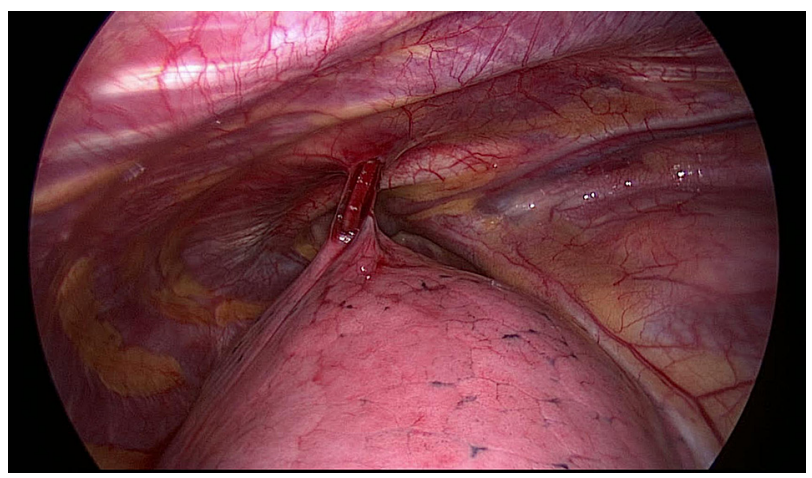

FIGURE 2. Thoracoscopic view of a foreign body penetrating the chest wall and lung.

2. Villavicencio RT, Aucar JA, Wall MJ Jr. Analysis of thoracoscopy in trauma. Surg Endosc. 1999;13:3-9. 